\title{
8
}

\section{HEALTHY AND CARING CITIES}

\section{Accessibility for All and the Role of Urban Spaces in Re-Activating Capabilities}

\author{
Elena Marchigiani
}

\section{Introduction: Accessibility for All}

Today, life in cities suffers from three main, interconnected critical factors: the increase of social and economic imbalances; the rise of environmental and climate risks; and the growth of spatial segregation. For vulnerable and less well-off social groups this segregation is also due to inefficiencies in public transport and reduced mobility toward city cores and poles of services and jobs; as well as to the extension of spatial obstacles preventing accessibility to 'public welfare facilities'-green and public spaces, social and healthcare, education and cultural centers - by fragile dwellers (the elderly, children, persons with disabilities, etc.). This conceptualization of the 'urban question' strongly links inequalities to the uneven opportunities offered to large parts of the population to independently reach their psychological and physical well-being and to improve their wealth and cultural capital, through an inclusive access to urban services (Secchi 2013; Soja 2010). All over Europe, the growth of urbanization and aging trends make future scenarios even worse, where further demand for care and social provision will produce severe impacts on the economic sustainability of public welfare policies. ${ }^{1}$

With this perspective, the upgrade of 'urban accessibility' gains a strategic role in helping public administrations fight against multiple inequalities. Accessibility is here understood as the material organization of public spaces and facilities allowing their usability by the largest number of persons, through autonomous soft mobility - mainly by walking, cycling, or using a wheelchair, combined with public transport. The focus is on the spatial connection and comfort of the routes that a person covers every day (from their house to collective places and welfare resources), and on the overall quality of the urban environment that can support social interaction and accommodate the needs of individuals while enabling their different motor, cognitive, and sensory capabilities. Under the pressure of just claims by people with disabilities, in the past decades 'accessibility for all' has become a recurring slogan. However, urban policies and design still struggle to go beyond targeted solutions for specific populations of users and to rethink infrastructures and public spaces in order to provide everyone-as far as possible-with equal well-being conditions. 
Since the last years, the impacts of the COVID-19 pandemic have put these issues at the core of the debate. Despite differences in national contexts, social/physical distancing and limitation in the use of public spaces and services are producing significant effects on the psycho-physical health of those who already experience major vulnerabilities (due to age, loneliness and illnesses, lack of economic and social resources, poor housing conditions, etc.). The situation is often worsened by the previous inadequacy of spatial assets and accessibility to places where fundamental social, healthcare, and education facilities are provided. Due to the reduced capacity of public transport, the requirement for soft mobility infrastructures is even greater, giving citizens the opportunity to safely move and interact with other persons, while performing healthy behaviors. In this sense, the expected impacts of the pandemic on a deep restructuring of welfare provision further highlight the relations between urban transformations dealing with accessibility and the 'spatial dimensions of care' that materialize where welfare displays its services (Power and Williams 2019). The invitation is to innovate the ways public facilities are interconnected and related to their urban contexts.

Beyond a concept of care exclusively referring to medicalization and remedial interventions, the proposed perspective is that of a proactive and 'preventive urbanism' (Dorato 2020). The city is read as an 'environment of care,' where urban space supports daily practices for active movement and lifestyles, preventing diseases and health disorders, and equally giving citizens access to commodities and services. Since the nineteenth century, the 'corporeal dimension' has been a concern of urbanism and public health policies (Bianchetti 2020). Today, the issue of cities accessible for all as 'healthy and caring cities' brings the topic back to the center of debate about the complex interactions between different bodies and the ways cityscapes are organized. This chapter questions how accessibility for all can become a structural component of urban policies supporting a people-centered and spatialized work of care, whereas the design quality and usability of soft mobility infrastructures and welfare facilities are meant to enhance individuals' capabilities to actively reach their own well-being. The remaining sections: (1) offer a theoretical overview on how these issues relate to those of urban justice and healthy cities; (2) describe the conceptual frame of empirical research on cities accessible for all as 'proactive cities'; and (3) provide inputs for public policies and spatial solutions resulting from participatory design in an Italian case study. From a post-pandemic perspective, conclusions further reflect on (4) how caring cities prompt stronger integration of urban policies dealing with accessibility and welfare services provision.

\section{Urban Justice, Health, and Spatial Accessibility}

Accessibility for all to public spaces and facilities for education, social, and healthcare is still far from being recognized as a fundamental ingredient of urban planning and policies. However, discussion and practical experience have recently grown worldwide, helping re-frame the 'right to the city' - in the terms of inclusive use of urban space-into a broader debate on 'urban justice' and on the 'ethic dimensions' of spatial, social, and economic life in the cities (Fainstein 2010). Today, a variety of disciplines question to what extent the ways in which to manage accessibility influence the expression of a person's 'capabilities' to achieve well-being (Sen 1987), while treating with 'respect' individuals' different bodies and practices, needs, and potentials (Sennett 2003).

For some time now, sociological reflections have focused on how the difficulties in moving across spatial and social urban contexts contribute to generating severe inequalities (Sheller 
2018). When talking about "motility," attention is directed to the active role that inhabitants can perform in the city in relation to the material configuration of the places they live and work in (Kaufmann 2011: 37-46). Far from simplified environmental determinism, motility is pointed out as a 'conditioned,' 'conditioning,' and 'enabling capital.' It takes effect when a person's specific physical movement capabilities match with adequate levels of accessibility to urban assets. In turn, the degree of expression of 'motility capital' affects the development of additional capabilities, aimed at adapting one's lifestyle to contextual conditions. The presence of spaces that not only welcome but also stimulate these abilities can eventually lead to new social practices, which go beyond mere adaptation; this is an important aspect when rethinking urban welfare through citizens' active involvement.

The direct influence of spatial accessibility over the promotion of cities' and citizens' wellbeing is likewise highlighted by the World Health Organization's (WHO) motto "healthy places-healthy people," stressing the link between the social determinants of health and the urban environmental conditions (Commission on Social Determinants of Health 2008: 60). The integration of these dimensions drove the approval of the International Classification of Functioning, Disability, and Health (WHO 2001), the Convention on the Rights of Persons with Disabilities (United Nations 2006), and the European Disability Strategy 2010/2020 (European Commission 2010), where Universal Design (UD) is defined as the conception of products, environments, and services to be usable by all people, to the greatest extent possible, without the need for adding specialized devices. According to UD, disability is not a condition intrinsic to a person, but the result of the interaction with everyday living spaces (Arenghi et al. 2016); it can, therefore, temporarily or permanently affect everyone, through different phases of life.

These considerations show how the issues of accessibility can hardly be separated from the implementation of spatial solutions addressed to heal the vulnerable conditions of a growing number of city dwellers. The spread of soft mobility (mainly walking and cycling) - connecting green and public spaces, social and healthcare, education and cultural facilities - helps tackle many challenges: from the impacts of vehicular transport on environment and climate; to the promotion of physical activity to reduce the increase in chronic diseases induced by sedentary lifestyles and aging trends. It is precisely from this multifaceted perspective that spatial accessibility is one of the leading issues of future urban agendas, calling for stronger relationships among social inclusion, environmental, and public health (United Nations 2016b). 'Healthy Cities' (Tsouros 2015), 'Active Cities' (Nike 2015), and 'Inclusive Cities' (Shah et al. 2015) are today only some of the labels used by international networks and design efforts, integrating a variety of actions: the refurbishment of public spaces as usable by people with different abilities; the combined implementation of mobility, green and healthy infrastructures, and of equipment for outdoor motor and sports activities; and the rethinking of the spatial setting of social and health-care facilities. Although the solutions these interventions propose are diverse, they all emphasize the role that an extended daily usability of city spaces plays in providing inclusive and healthy life conditions.

\section{Proactive Cities as Cities of Care}

Since 2019, at the University of Trieste, the aim of the research project Proactive City: The City as a Gym for Active Design ${ }^{2}$ has been to outline integrated planning and design approaches to the topic 'accessibility for all and the city,' with the aim of making urban spaces usable by 
persons with different motor, visual, hearing, and cognitive capabilities. Beyond the mitigation of the impacts of single physical and perceptual barriers, the research mainly focuses on an interpretation of 'cities as gyms.' Namely, cities as places where the upgrading of public spaces and facilities is part of integrated urban regeneration strategies and welfare policies, aimed not just at removing obstacles to accessibility, but at offering individuals the material conditions to move independently and to perform healthy behaviors, while respecting their diverse bodies, genders, cultural habits, and social and economic needs. If COVID-19 has highlighted the growing risk of pandemics, the increase of urban population suffering from temporary/stable disabilities and chronic pathologies can be assumed as a current and worsening condition of 'ordinary epidemics' that must be more effectively tackled. The perspective of accessibility for all helps pay major attention to the spatialized dimensions of public welfare policies (the physical quality and urban distribution of facilities), understood as strategic conditions to efficiently provide everyday care to the largest number of persons.

A fundamental ingredient to make cities proactive is joining actions on 'places and people': that is, on the physical configuration of urban space, on the ways public services are provided, and on the role assigned to citizens as services' co-producers. By supporting active mobility across and in-between public spaces, social and health-care equipment, proactive cities do not only help counter the effects of diseases and disabilities, but also contribute to prevent medicalized care and to enhance the performance of public welfare. Talking about proactive cities thus helps set aside a mere sanitary approach such as that offered by isolated and specialized structures for 'passive care receiving' (i.e., hospitals and health centers, nursing homes), where the limited availability of the public offerings and the costs on the private market exacerbate inequalities in the access to assistance (Marmot 2015). The increase of soft mobility infrastructures and of public spaces for healthy movement-combined with a widespread and territorialized setting of welfare facilities, and a better usability of their indoor and outdoor spaces - can provide a complementary and ordinary way to take care of both persons and city environments, to support aging at home, and to postpone the need of institutionalized solutions (de Leonardis and Monteleone 2007). In this view, the reference to the 'capability approach' prompts rethinking public caregiving work by recognizing individuals as "active agents of change, rather than as passive recipients of dispensed benefits," within a collaborative perspective where institutional, social, and personal capitals are jointly engaged (Sen 1999: xiii). Public welfare does not retreat from its responsibilities. In fact, it further enlarges its action domains, to transform facilities from places that deliver ready-made services into 'proactive devices' interacting with a diversified set of urban spaces, where healthy and care-full practices can be customized to persons' demands also through social interaction, mutual help, and the performance of outdoor physical exercise (Gallio and Cogliati Dezza 2018). The aim is to offer citizens the opportunity to freely choose and use the urban resources and amenities they need "to live full and creative lives, developing their potential” (Nussbaum 2011: 185).

\section{Accessibility for All in Practice: Approaches and Design Solutions}

Within the framework of urban transformations and policies, accessibility to collective spaces and welfare services can be translated into many operational fields. Proactive City takes on an interdisciplinary approach, involving different expertise: from planning and inclusive spatial design, to healthcare and rehabilitative therapy. In addition, Proactive City is oriented toward a robust interaction between theory and practice, according to a 'reflective practitioner's' attitude 
(Schön 1984). In this view, empirical research activities are meant to develop two intertwined paths: the definition of general approaches to innovate public policies and the exemplification of spatial solutions through the participation of local stakeholders and administrations.

\section{Three Shifts in Perspective for Public Policies}

The critical analysis of over 100 Italian planning and design experiences helped Proactive City recognize the main innovations needed in planning processes to fill the gaps that still prevent an inclusive usability of public spaces and facilities (Istituto Nazionale di Urbanistica 2020).

A first shift in perspective is from the implementation of targeted and punctual interventions to ease the mobility of disabled persons toward the planning of interconnected spatial networks allowing accessibility for all to urban equipment. In many European cities, twentieth-century welfare state policies have produced a rich legacy of public facilities: parks and gardens, sports fields, schools and libraries, civic and cultural resources, social and healthcare centers. This spatial capital can be defined as a 'public city', made by the components of urban contexts where contemporary daily routines and collective life unfold. However, their construction according to purely quantitative and functional planning and design standards has frequently led to separate and disconnected plots and buildings that are often difficult to access. The actual norms for the retrofitting of single open spaces and edifices according to the needs of persons with disabilities are therefore not sufficient. The issues of accessibility for all invite the introduction of new qualitative criteria fostering well-designed soft and inclusive mobility routes in between facilities. Understanding these routes as a widespread urban system can help reshape the spatial elements of the public city into an overall 'social and care infrastructure,' meant as a welfare service itself, a material support for social relations and extended well-being conditions.

A second shift consists of disrupting the traditional separations among the public administrative sectors and interventions dealing with spatial transformations (urban planning and traffic, public works for the maintenance and design of infrastructures, built and open spaces), public welfare and housing policies, as well as with the management of sports equipment, and the enhancement of landscape and environmental resources. Talking about a city accessible for all means questioning how to make urban facilities as accessible as possible, on foot, by bike, by public transport, by internet, according to people's different capabilities. It means reorganizing the ways services are provided to make them closer to those who need them most and cannot reach them on their own. Starting from the spatial constraints of places and based on the resources and demands of the persons who actually live there, accessibility for all therefore becomes a powerful driver to replace the siloed thinking that still characterizes administrative routine practices with more integrated approaches to urban governance, aimed at building solutions that are better tailored to their contexts and to citizens' everyday needs.

Finally, a third shift in perspective is from 'designing for' to 'designing with. 'Designing for' means improving the relationships between urban assets and people taken not as consumers, but as active users and producers - through their bodies and social practices - of their material living conditions (de Certeau 1984). However, what we call the 'perceived usability of a place' goes beyond the absence of sensory and architectural barriers. It refers, instead, to articulated physical and behavioral variables, whose impacts differ according to a person's overall capabilities, and profoundly influence the ability to use a specific urban space and facility. To be 
effective, spatial solutions should therefore be built through continuous processes of 'designing with,' open to the contribution of the 'common knowledge' of those who more greatly suffer from the consequences of disabling environments. When designing cities accessible for all, methods of direct collection and interpretation-through participatory surveys-of qualitative information on the actual usability of mobility infrastructures, public spaces and facilities thus become strategic. The right to creativity of a designer has in fact to be carefully negotiated with the judgment expressed by a variety of stakeholders, who should be invited to co-build and co-validate the different steps of the design process from its initial phases-not just during formal presentation events of already developed proposals, as still usually happens for 'ordinary' public urban transformations.

\section{The Design of Urban Spaces as a Social and Care Infrastructure}

The opportunity to further work on these issues was given by the organization of a 'research by design' workshop with the local municipality of a pilot city in the Italian region Friuli Venezia Giulia. ${ }^{3}$ The city of Grado is a tourist destination representative of other small urban centers, with a strong seasonal change in urban habits. The local administration is implementing projects for public spaces, with specific attention to green networks. A plan for public works to remove architectural barriers to pedestrian accessibility has been recently adopted, and a plan for sustainable urban mobility is under construction. However, no real dialogue between these projects is set yet.

During a two-week workshop, professors and students from the University of Trieste lived in Grado, walked and cycled its urban spaces, met technicians from the municipality and the region Friuli Venezia Giulia, took part in facilitating participatory surveys with disabled people's associations. Training seminars focusing on solutions for active and accessible cities were given by researchers and professionals, with the aim to support more informed involvement of local public officers and stakeholders. Meanwhile, students, professors, and technicians worked on design proposals for a 'green, healthy, and accessible urban route,' connecting residential parts of the city to parks and pedestrian areas located near the beach (see Figure 8.1). The objective was to draw a 'social and care infrastructure, namely, to integrate this itinerary into a broader system of open spaces and existing paths for cycling and walking; and promote the reuse of vacant lots for sports activities and an urban regeneration strategy for the whole city center. The slogan of the workshop was to imagine Grado not only as accessible for all, but as a 'small capital of healthy life,' where spaces and services work in an integrated manner, offering both tourists and residents the opportunity to move safely and perform outdoor activities.

The workshop results showed how the issues of proactive cities can be translated into integrated design solutions. By working on a site-specific scale, the new urban route took form through a variety of spatial devices for the redesign of existing streets, paths, and public open spaces. The selection of the places to refurbish was driven by considerations on an urban scale. Proposals took available public facilities as the keystones of the whole system of soft mobility: schools, parks, sports equipment, and health-care facilities for the elderly. In order to connect them, solutions converged, stressing wherever possible the increase of pedestrian areas and of separate itineraries dedicated to bikes, combined with the reorganization of parking facilities and public transport services. When the co-presence of different modes of mobility in the same road spaces could not be avoided, the proposal was to design ' $30 \mathrm{~km} / \mathrm{h}$ streets': 

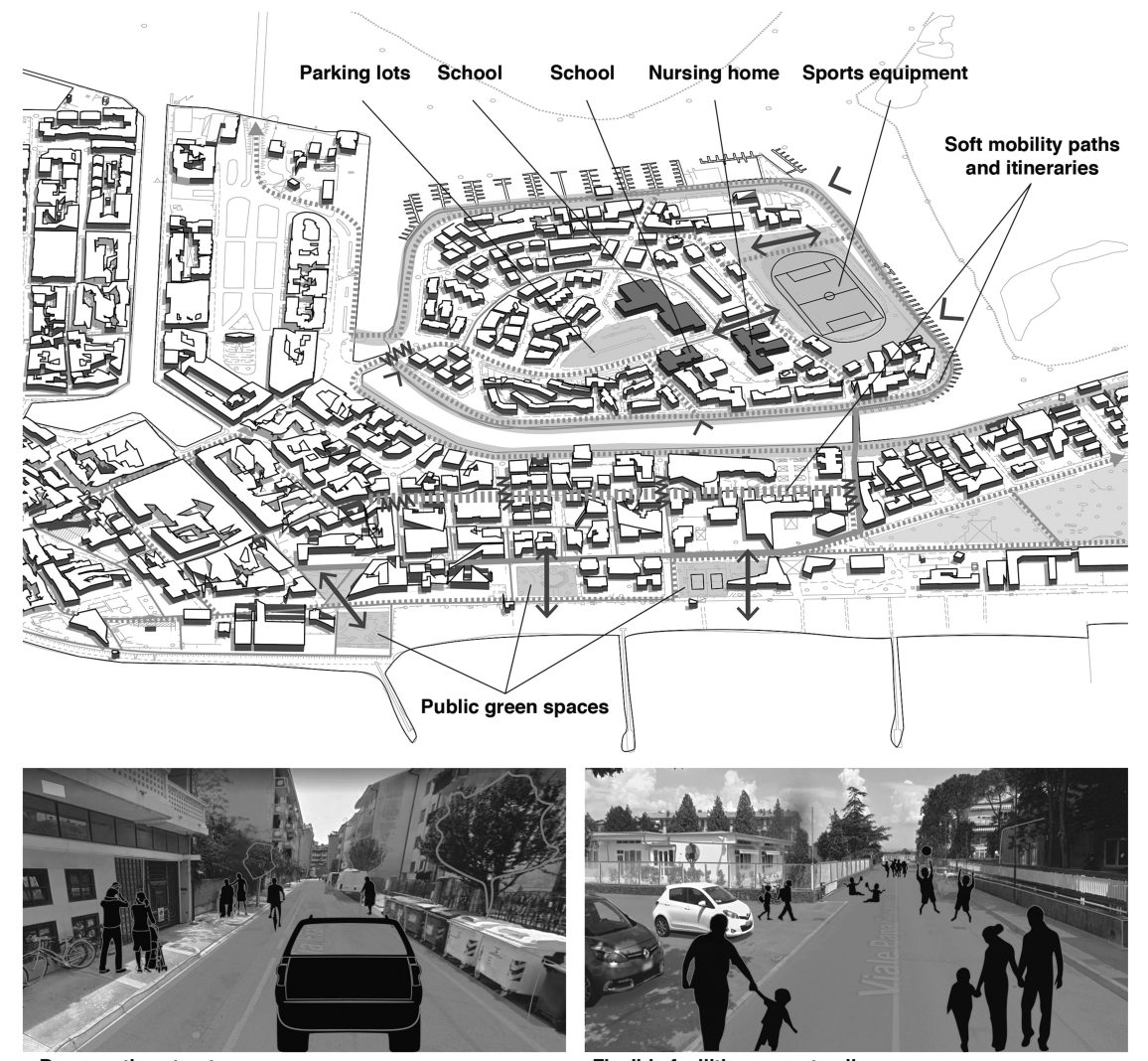

Democratics streets

Flexible facilities, open to all
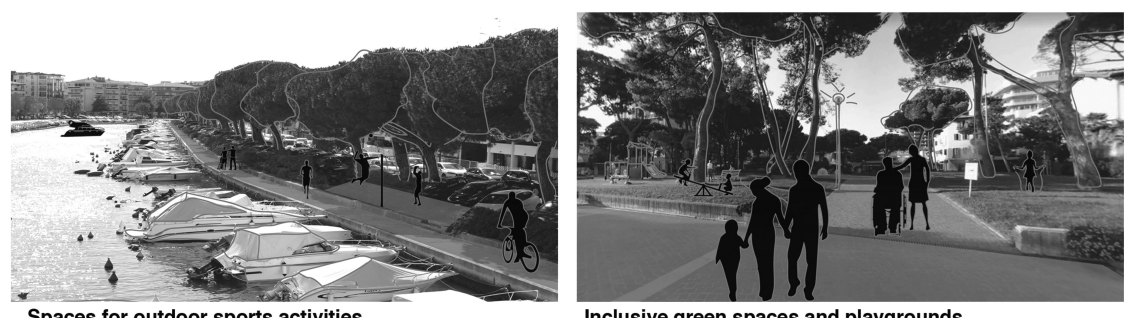

Spaces for outdoor sports activities

Inclusive green spaces and playgrounds

FIGURE 8.1 Design workshop in Grado: general master plan and strategies for the 'green, healthy, and accessible urban route.' Source: Project documentation of Proactive City at University of Trieste, Elena Marchigiani, principal investigator, 2019.

public spaces that are intended to protect the most vulnerable users (pedestrians and bikers), by hosting cars in reduced vehicular areas, adding chicanes and trees to articulate the street section, and forcing drivers to lower their speed (Adminaité-Fodor and Jost 2020). A common ingredient to all the interventions was the creation of a continuous system of pedestrian crossing platforms and pavements, where the choice of keeping them at the same level, of using smooth surface materials, and the location of street furniture were meant to help orientation and remove obstacles, not only for persons with motor and sensory disabilities, but for anyone (see Figure 8.2). 

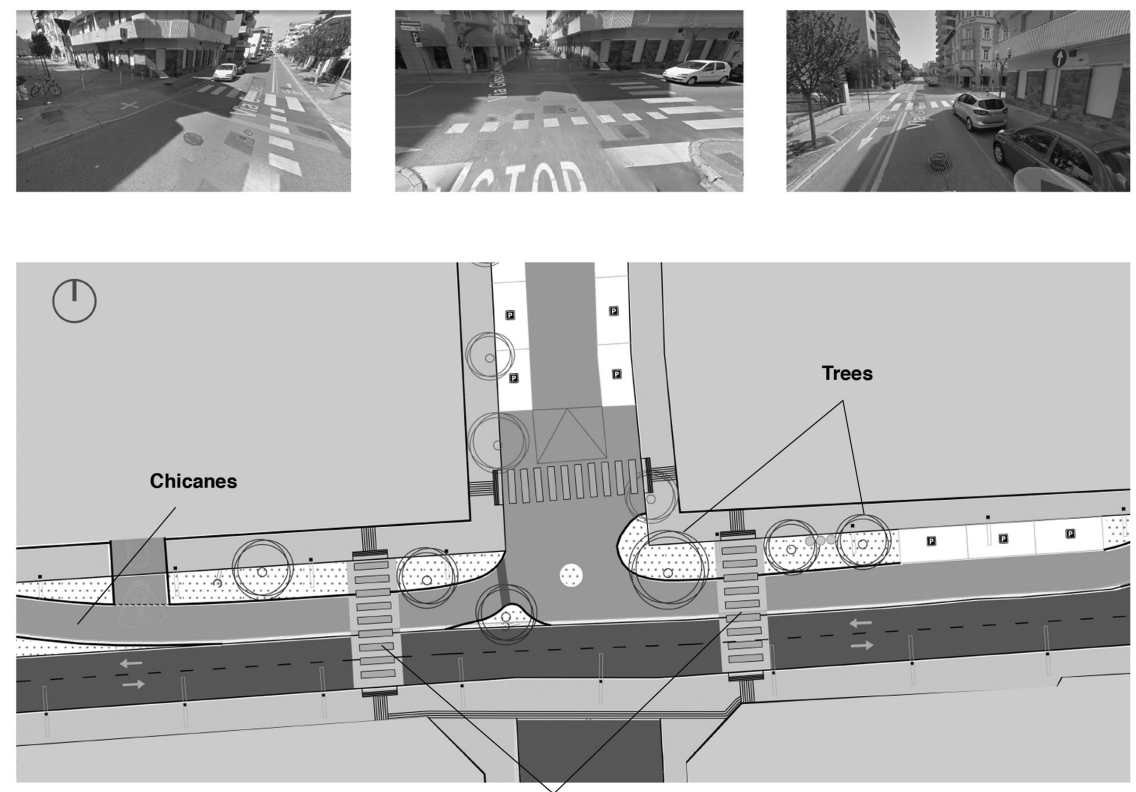

Crossing Platforms
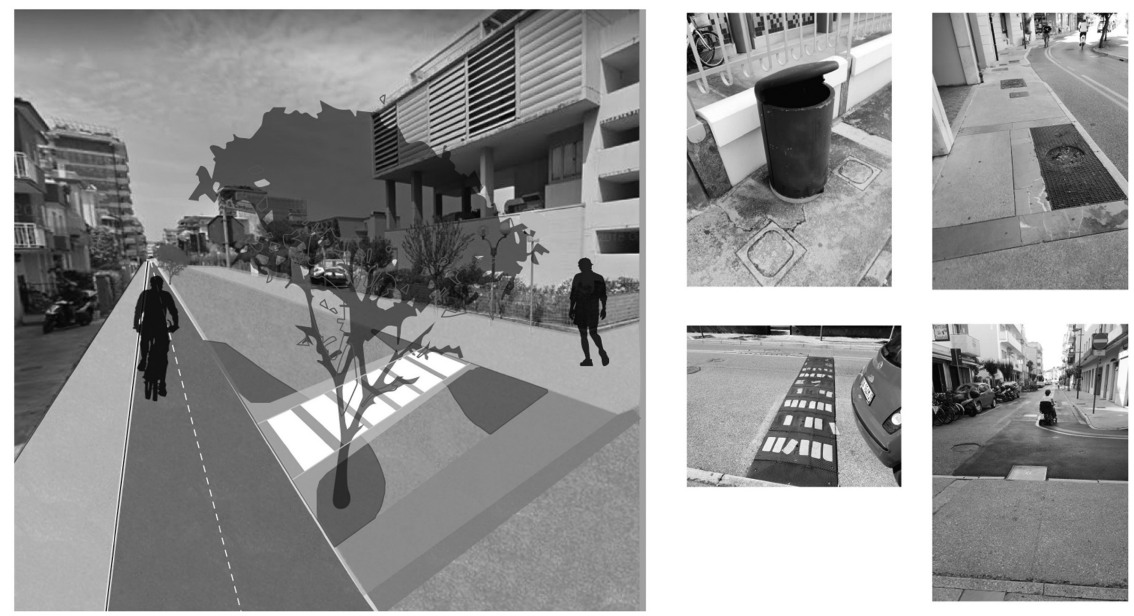

FIGURE 8.2 Design workshop in Grado: $30 \mathrm{~km} / \mathrm{h}$ streets as accessible and democratic urban spaces. Source: Project documentation of Proactive City at University of Trieste, Elena Marchigiani, principal investigator, 2019.

In making the whole strategy more effective, careful work on the spaces lying among soft mobility infrastructures, buildings, and plots hosting public facilities played an important role. Proposals focused on how to open up the fences of existing schools and sports equipment and to redraw the often poorly designed in-between spaces that separate them from those for walking, cycling, and public transport stops, in order to multiply the services that these facilities provide, and to offer them to a larger variety of users (see Figure 8.3). The general aim was to shape a new system of public and green, flexible, and adaptable, 'loose spaces,' where uses 


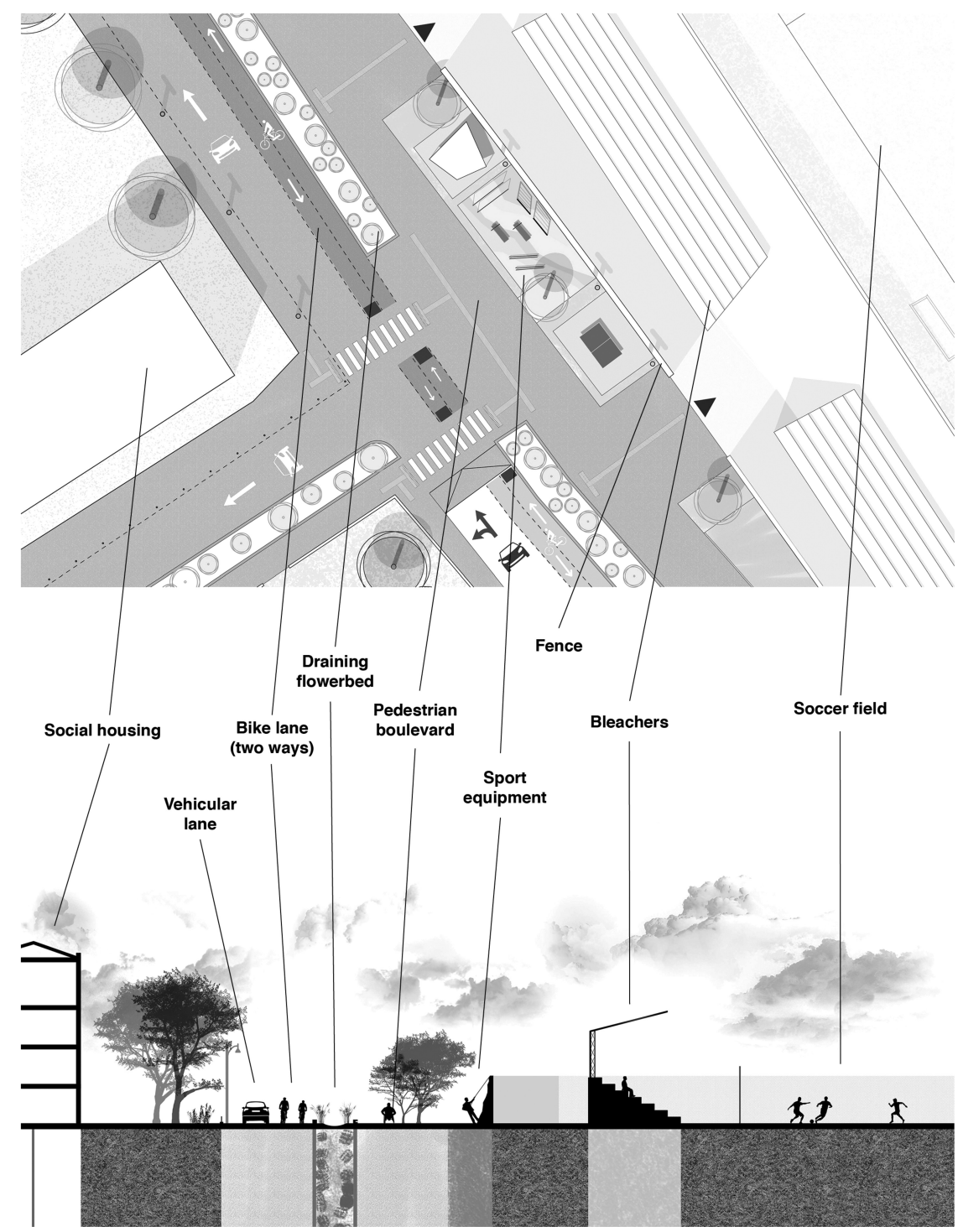

FIGURE 8.3 Design workshop in Grado: spaces in-between sports equipment, schools, and soft mobility infrastructures. Source: Project documentation of Proactive City at University of Trieste, Elena Marchigiani, principal investigator, 2019.

are not pre-determined by rigid spatial layout and casual encounters can take place; where inclusive playgrounds and equipment for outdoor activities are not conceived as intrusive furniture but as an integral part of multitasking urban spaces, inviting people to freely act in the city (see Figure 8.4) (Franck and Stevens 2007).

In all the projects, the expansion of green areas and vegetation to make the urban scene more resilient to climate change was among the main ingredients, showing how accessibility, health, and environmental issues can be jointly addressed in ordinary interventions in public 


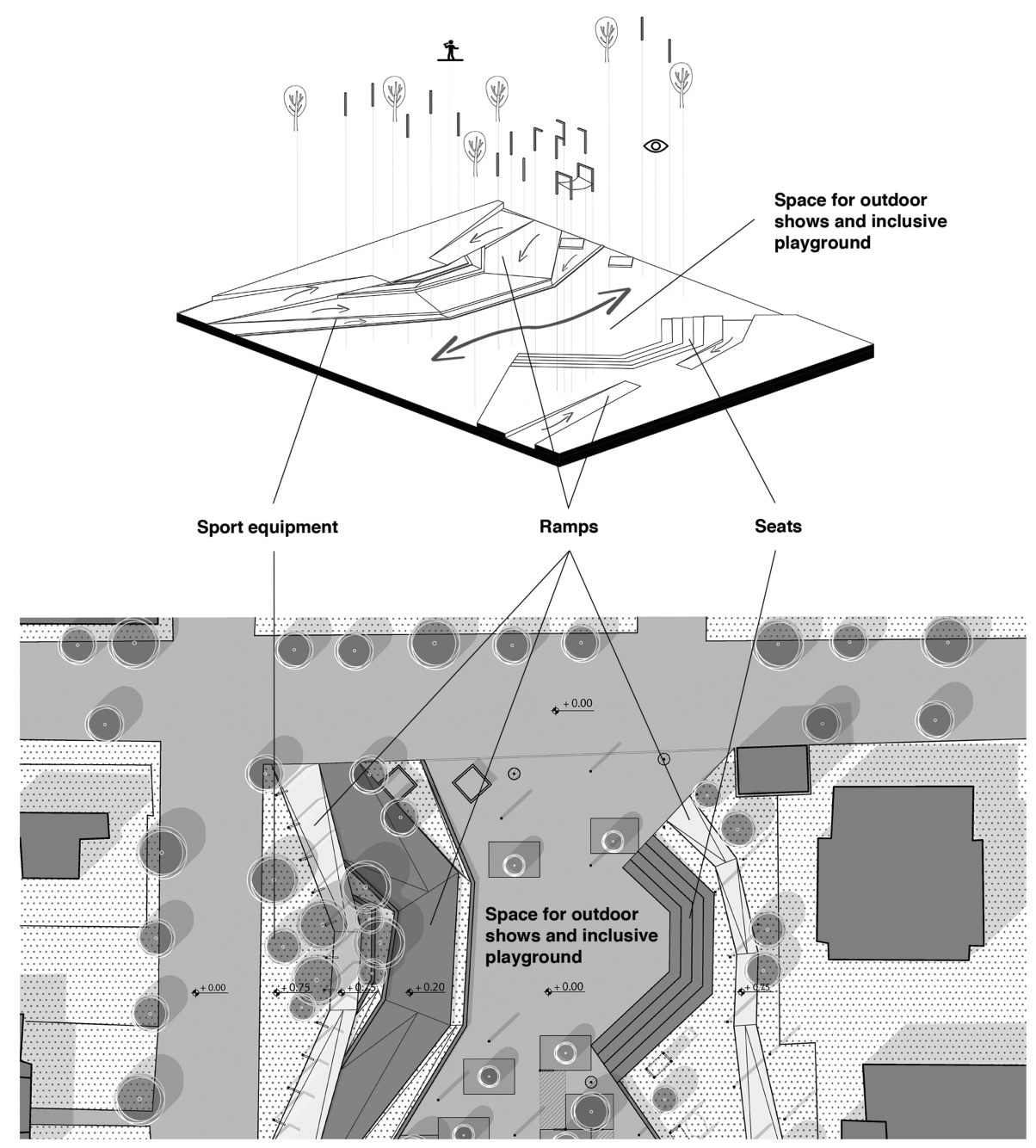

FIGURE 8.4 Design workshop in Grado: inclusive playgrounds and multitasking urban spaces. Source: Project documentation of Proactive City at University of Trieste, Elena Marchigiani, principal investigator, 2019.

spaces. However, trying to match a variety of often-opposing demands and uses concretely proved to be a "wicked problem," with many reverberations in spatial justice, and which needed to be addressed within a well-argued mediation process (Rittel and Webber 1973: 160-167). Specifically, the workshop strengthened awareness that inclusive mobility in public spaces can be achieved only by designing without barriers from the very beginning, taking the perspective of the most vulnerable citizens to conceive places that are usable by everyone, and trying to anticipate in advance conflicts among different modes and capabilities of moving: "Democratic streets [and public spaces] are not possible without a democratic process charged with shaping their character and form," and addressed to build site-specific solutions that respect uses and users' diversity (Francis 1987: 37). 


\section{Conclusions: Toward Post-Pandemic People-Centered Cities}

As COVID-19 quarantine and distancing measures have shown, the reduction of physical accessibility to public spaces and services accounts for a significant worsening of social inequalities in health and care provision. If the management of post-lockdown phases in cities around the world is resulting in pop-up bike lanes and temporary pedestrian areas as tactical and expedited reactions to a limited use of public transport, more structural and longlasting adaptation of spaces and connections according to accessible for all criteria cannot be postponed. Otherwise the risk is - again - not to consider the importance that the material interdependence between different bodies and places plays in the definition of care and equity conditions, and therefore to miss the opportunity to use the pandemic as the driver to strategically rethink the ways urban environments are organized (Pineda and Corburn 2020).

In fact, when referring to inclusive design, the discourse on accessibility still suffers from a retreat into technical solutions that confine the movement of persons with disabilities to dedicated spaces, thus producing 'spatial stigmatization' and preventing social interaction. What the results from Proactive City's research show is that acknowledging accessibility for all as universal right forces us to understand detailed spatial devices as ordinary and interconnected components of innovative urban regeneration processes. To reach this goal, accessibility has to be taken as a basic ingredient of general town plans, and of the many interventions that affect the usability of collective spaces and facilities (from traffic and public transport, to the upgrading and equipment of public spaces and buildings). Moreover, spatial works favoring accessibility can be relatively cheap and implemented through time, operation after operation; this offers a way to cope with the current limits in public budget for urban renewal. In other words, if the enduring conditions of 'austerity' (Fanelli et al. 2017) and the increase of social demands put the welfare state under an almost unbearable stress, Proactive City stresses that solutions do not necessarily have to be found in the withdrawal of public action or in neoliberal paradigms. According to a capability approach, answers can also be sought in a people-centered reorganization of spatial equipment and services, and of their accessibility, within a framework of innovative "caring with" models of public welfare (Tronto 2017: 32).

The pandemic has stressed how our lives are shaped by structural uncertainty, where combined health, environmental, climatic, and social risks will increasingly elude forecasts and standardized remedies. It is therefore no coincidence that the attribute of 'preparedness' is today often linked to urban policies (Lakoff 2017). Beyond a mere remedial approach, the challenge is to radically reorient public action toward "socio-ecological care," and to integrate preparedness with active prevention (Bifulco and Centemeri 2020: 3). From this perspective, understanding accessible cities as inclusive environments of care prompts rethinking the physical assets and connections among public spaces, social and health equipment, and ecological resources as a service itself, and as a material support for healthier habitats and lifestyles. The aim is both to give everyone the opportunity to autonomously and safely use city spaces, and to maintain as much as possible the operability of welfare services-in both 'normal' and emergency conditions.

\section{Notes}

1 In Europe, by 2050, nearly $80 \%$ of the population will live in urban contexts, and people aged 80 or over will comprise $11.4 \%$ of the population (Margaras 2019: 2). In the world, 15\% will be persons with disabilities (United Nations 2016a: 6). 
2 Proactive City is coordinated by the author, and involves Sara Basso, Barbara Chiarelli, Ilaria Garofolo, Lucia Parussini, Roberto Prandin, and Valentino Pediroda.

3 The workshop took place in July 2019. It was coordinated by the author, with Sara Basso, Barbara Chiarelli, Ilaria Garofolo, and Valentina Crupi and involved students from Architecture and Engineering of the University of Trieste (Valentina Andriolo, Margherita Caiffa, Marco Facciuto, Riccardo Gergolet, Claudia Gruarin, Stela Guni, Davide Gurtner, Maria Teresa Manzara, Manuel Milone, Giulio Pastoricchio, Giulia Piacente, Francesco Schiava, Annamaria Spezzigu, and Alessia Visintin). Maria Antonietta Genovese was the contact person from the municipality of Grado.

\section{References}

Adminaité-Fodor, D. and Jost, G. (2020) How Safe Is Walking and Cycling in Europe? [Online]. Brussels: European Transport Safety Council. Available at https://etsc.eu/wp-content/uploads/PIN-Flash-38 _FINAL.pdf [Accessed 06 September 2021].

Arenghi, A., Garofolo, I. and Lauria, A. (2016) On the Relationship Between 'Universal' and 'Particular' in Architecture. In H. Petrie, J. Darzentas, T. Walsh, D. Swallow, L. Sandoval, A. Lewis and C. Power (eds.) Universal Design 2016: Learning from the Past, Designing for the Future. Amsterdam: IOS Press, pp. 31-39.

Bianchetti, C. (2020) Bodies: Between Space and Design. Berlin: Jovis.

Bifulco, L. and Centemeri, L. (2020) Città, preparedness e salute. Urban@it 1 [Online]. Available at https://www.urbanit.it/wp-content/uploads/2020/07/BP_Bifulco_Centemeri.pdf [Accessed 15 December 2020].

Commission on Social Determinants of Health (2008) Closing the Gap in a Generation:Health Equity Through Action on the Social Determinants of Health [Online]. Geneva: World Health Organization. Available at https://www.who.int/social_determinants/final_report/csdh_finalreport_2008.pdf [Accessed 06 September 2021].

de Certeau, M. (1984) The Practice of Everyday Life. Berkeley: University of California Press.

de Leonardis, O. and Monteleone, R. (2007) Dai luoghi della cura alla cura dei luoghi. In R. Monteleone (ed.) La contrattualizzazione delle politiche sociali. Roma: Officina, pp. 165-182.

Dorato, E. (2020) Preventive Urbanism:The Role of Health in Designing Active Cities. Macerata: Quodlibet.

European Commission (2010) European Disability Strategy [Online]. Available at https://eur-lex.europa .eu/legal-content/EN/TXT/?uri=LEGISSUM\%3Aem0047 [Accessed 15 December 2020].

Fainstein, S. (2010) The Just City. Ithaca: Cornell University Press.

Fanelli, C., Tufts, S., Noonan, J. and Essex, J. (eds.) (2017) Austerity Urbanism and the Social Economy. Toronto: Alternate Routes.

Francis, M. (1987) The Making of Democratic Streets. In A. Vernez Moudon (ed.) Public Streets for Public Use. New York: Van Nostrand Reinhold Company, pp. 23-39.

Franck, K.A. and Stevens, Q. (2007) Loose Space: Possibility and Diversity in Urban Life. New York: Routledge.

Gallio, G. and Cogliati Dezza, M.G. (eds.) (2018) La città che cura. Meran: Edizioni alpha beta Verlag.

Istituto Nazionale di Urbanistica (2020) Città accessibili a tutti [Online]. Available at http://atlantecittacce ssibili.inu.it/ [Accessed 15 December 2020].

Kaufmann,V. (2011) Re-Thinking the City: Urban Dynamics and Motility. Lausanne: EPFL Press.

Lakoff, A. (2017) Unprepared: Global Health in a Time of Emergency. Berkley: University of California Press.

Margaras,V. (2019) Demographic Trends in EU Regions [Online]. Brussels: European Parliament Research Service. Available at https://ec.europa.eu/futurium/en/system/files/ged/eprs-briefing-633160 -demographic-trends-eu-regions-final.pdf [Accessed 06 September 2021].

Marmot, M. (2015) The Health Gap. London: Bloomsbury Publishing.

Nike (2015) Designed to Move:Active Cities [Online]. Available at https://participatoryplanning.ca/sites/ default/files/upload/document/tool/designed_to_move_pdf [Accessed 15 December 2020].

Nussbaum, M.C. (2011) Creating Capabilities. Cambridge, MA: Harvard University Press. 
Pineda, V.S. and Corburn, J. (2020) Disability, Urban Health Equity, and the Coronavirus Pandemic: Promoting Cities for All. Journal of Urban Health 97(2): 336-341.

Power, E.R. and Williams, J.M. (2019) Cities of Care: A Platform for Urban Geographical Care Research. Geography Compass 14(1). https://doi.org/10.1111/gec3.12474.

Rittel, H.W. and Webber, M.M. (1973) Dilemmas in a General Theory of Planning. Policy Science 4(2): 155-169.

Schön, D. (1984) The Reflective Practitioner: How Professionals Think in Action. New York: Basic Books.

Secchi, B. (2013) La città dei ricchi e la città dei poveri. Roma: Laterza.

Sen, A. (1987) Commodities and Capabilities. Oxford: Oxford University Press.

Sen, A. (1999) Development as Freedom. Oxford: Oxford University Press.

Sennett, R. (2003) Respect in a World of Inequality. New York: Norton and Company Inc.

Shah, P., Hamilton, E., Armendaris, F. and Lee, H. (2015) World: Inclusive Cities Approach Paper [Online]. Washington, DC: The World Bank. Available at https://documents1.worldbank.org/curated/en/4 02451468169453117/pdf/AUS8539-REVISED-WP-P148654-PUBLIC-Box393236B-Inclusive -Cities-Approach-Paper-w-Annexes-final.pdf [Accessed 06 September 2021].

Sheller, M. (2018) Mobility Justice: The Politics of Movement in an Age of Extremes. London: Verso.

Soja, E.W. (2010) Seeking Spatial Justice. Minneapolis: University of Minnesota Press.

Tronto,J.C. (2017) There Is an Alternative: Homines Curans and the Limits of Neoliberalism. International Journal of Care and Caring 1(1): 27-43.

Tsouros, A.D. (2015) Twenty-Seven Years of the WHO European Healthy Cities Movement: A Sustainable Movement for Change and Innovation at the Local Level. Health Promotion International 30(1): 13-17.

United Nations (2006) Convention on the Rights of Persons with Disabilities [Online]. Available at https:// www.un.org/development/desa/disabilities/convention-on-the-rights-of-persons-with-disabilities .html [Accessed 15 December 2020].

United Nations (2016a) Good Practices of Accessible Urban Development [Online]. Available at https://ww w.un.org/disabilities/documents/desa/good_practices_in_accessible_urban_development_octobe r2016.pdf [Accessed 15 December 2020].

United Nations (2016b) The Sustainable Development Agenda 2030 [Online]. Available at https://sustain abledevelopment.un.org/post2015/transformingourworld [Accessed 15 December 2020].

World Health Organization (WHO) (2001) International Classification of Functioning, Disability and Health [Online]. Available at: https://www.who.int/classifications/icf/en [Accessed 15 December 2020]. 